Media Industries $5.2(2018)$

\title{
Games without Frontiers: Streaming Sports and the Evolution of Digital Intermediaries
}

\author{
Steven Secular ${ }^{1}$ \\ UNIVERSITY OF CALIFORNIA, SANTA BARBARA \\ steve.secular [AT] gmail.com
}

\begin{abstract}
As television has evolved into a global online medium, content owners from around the world increasingly rely on intermediary firms to program and manage their streaming platforms. Although such platforms feature the names of companies like HBO and ESPN, it has been the intermediaries that construct them, like BAMTech and NeuLion, that set the parameters of how audiences engage with streaming video. This article highlights the growth of intermediaries beginning in the 1990s, when media companies began to seek expert firms to help them put content online. Intermediaries, given their experience working in sports media, became experts in geolocation and audience analytics. As television has transitioned into an online medium, the leverage of the intermediary has grown with it, as reflected in Disney's recent purchase of BAMTech. The study of intermediaries, therefore, illuminates the contributions of an obscured but immensely influential party in the process of global television distribution.
\end{abstract}

Keywords: Intermediaries, Internet, Distribution, Streaming, Global

A global media distribution center sits in an unassuming office park in Plainview, New York. NeuLion programs and oversees the streaming platforms for the National Basketball Association (NBA), the National Football League (NFL), Univision, and China Central Television (CCTV), among other media companies from around the world. The streaming video enjoyed by a basketball fan in Brazil streaming the Houston Rockets-Oklahoma City Thunder game, a football fan catching replays on a train in France, or a RugbyPass subscriber in China, all emanate from that building on Long Island. As internet-distributed television grows more prominent on a global scale, and as content owners and traditional distributors alike try to determine the most lucrative way to move forward, NeuLion is but one example of a new player that has emerged in this media ecosystem: the streaming intermediary. 
When content owners seek to put their content online, they turn to these intermediaries to program and manage their branded streaming platforms. HBO and ESPN, for example, lacking the appropriate infrastructures for their HBO Now and WatchESPN ventures, both turned to the same company: the Major League Baseball-owned BAMTech (originally Baseball Advanced Media). In August 2016, BAMTech made headlines when Disney had finally had enough of leasing the firm's services for its ESPN platform and purchased 33 percent of the company for US\$1 billion. One year later, in August 2017, Disney bought another 42 percent for US\$1.58 billion, valuing the company at US\$3.75 billion. ${ }^{2}$ In a streaming media economy, the streaming intermediary has become immensely valuable. If a content owner wants its content streaming around the world, it needs an intermediary to do that work.

Amanda D. Lotz describes how "internet distribution requires an entity to organize and deliver programming," using the term "portal" for the "crucial intermediary services that collect, curate, and distribute television programming via internet distribution," such as Netflix, Hulu HBO Now, and CBS All Access. ${ }^{3}$ These intermediaries, though, require additional intermediaries to program and manage this collection, curation, and distribution. Such companies are "transparent," as Joshua Braun describes them, in that they minimize their own branding in service of their client. Although the HBO name is on the marquee of the HBO Now platform, it is BAMtech that designed and operated it. This article, therefore, expands on Braun's work on the streaming intermediary and examines their productive role in the development of global internet television. Braun, in examining the "infrastructures that underlie" streaming video, notes that these intermediaries "increasingly enable, but also structure, the distribution of video online" and that they ultimately "stand to become just as essential to the media ecosystem as cable providers and broadcast affiliates before them." This is a significant claim about the power dynamics of the contemporary media industries and one that this article will further demonstrate.

Transparent intermediaries hold a fundamental position within the infrastructure of streaming video, opening and closing possibilities of how audiences view and engage with content. In doing so, these firms complicate how we conceive of content ownership and media flows, which now involve the contributions of additional parties in the process of production and distribution. Lotz explains that the growing strategy "in which the content rights holder distributes directly to the consumer ... provides a far more efficient economic model." This is evident in the launches of HBO Now, CBS All Access, and ESPN+. Yet these portals require the work of specialists to operate them-to design and program their interface, encode the video, track and analyze audience behavior, set geo-restrictions, and oversee any problems with the finished front-end video. Sports programming, specifically, also requires the editing of highlight packages and condensed versions of games.

Moreover, as US content owners have begun to build international versions out of their domestic platforms, and regional media companies from around the world have hired US intermediaries to build their streaming platforms, this process rearticulates questions of cultural influence and homogeneity. It is not simply content that flows across borders but digital platforms and their attendant algorithms. In examining global internet television, the streaming intermediary is an increasingly central element, overseeing the video encoding process that makes internet distribution possible and programming the interface that 
viewers engage. Focusing on the intermediary's involvement in digital distribution can thus reframe our understanding of streaming as a paradigm shift for owners and audiences alike.

At the same time, an historical approach to the streaming intermediary allows us to more fully historicize the streaming revolution. The crucial role of such intermediaries begins in the 1990s, as content owners start to experiment with putting their content online. The use of the internet as a new distribution technology required a level of technological knowledge that content owners were slow to adopt, relying instead on the experts and relinquishing some control in the nascent realm of internet distribution. These specialist firms-companies such as Starwave, AudioNet, and BackWeb-were able to leverage their knowledge of computer programming, digitization, and web architecture to become indispensable intermediaries in the business of internet distribution. They were hired to build the websites, digitize the content, parse the data, and balance the bandwidth loads.

Some companies provided all of these services to its clients, whereas others were more narrowly specialized. Starwave, for instance, constructed the entire multimedia platform for ESPN from the ground up, whereas AudioNet saw an opportunity in specializing in online audio streams for radio stations. BackWeb offered clients the technology for direct-toconsumer "push" content, which would collate select information from across the web and "broadcast" it to users' computers. ${ }^{6}$ As video streaming has become more globally accessible and television has evolved, the role of these intermediaries has only grown and deepened. NeuLion and BAMTech, for instance, fulfill the same role once played by Starwave and AudioNet. They develop streaming video platforms that feature the latest advancements in audience analytics and geolocation.

Media companies continue to rely on expert firms to facilitate the various essential functions of internet television. As these intermediary services continue to oversee the creation and maintenance of streaming platforms, and become more expensive to outsource, companies with enough capital to buy a preexisting one or build their own have sought to do so. NBC, for instance, launched Playmaker Media in May 2016 to service its own sports streaming operations as well as clients from outside Comcast-NBCUniversal. Turner Broadcasting System similarly acquired a majority stake in iStreamPlanet to bolster its streaming capabilities after its contract with MLB Advanced Media expired after the 2016 National Collegiate Athletic Association (NCAA) Men's Basketball Tournament. ${ }^{7}$ In January 2017, NBC and Turner even agreed to a strategic partnership in which these subsidiary services would work together and pool clients to better compete with BAMTech. ${ }^{8}$

Drawing on interviews I have conducted with personnel from NeuLion, the NBA, and Starwave, as well as site visits to NeuLion and the NBA, this article demonstrates how a greater emphasis on the work of intermediaries can more fully answer questions that have arisen from the growth of global internet-distributed television. While early agreements between content owners and digital firms were often experimental, serving as fact-finding operations, these arrangements have nonetheless become increasingly central as the distribution environment has evolved and required greater infrastructural capabilities. As internetdistributed video has become more widespread and its success more vital to content owners and internet service providers (ISPs), the intermediary firms that program the platforms and keep the video running properly wield considerable power over those who depend on their 
services, including the content owners and ISPs. Where appropriate, I refer to the first wave of intermediaries in the 1990s as "online intermediaries," to reflect their more generalized internet ambitions and capabilities, whereas "streaming intermediaries" is reserved for the more contemporary second wave, beginning in the early $2000 \mathrm{~s}$, for which streaming video became their most central service.

The streaming intermediaries, while they service the needs of particular clients, have as much invested in the global availability and popularity of their own platforms, for which the intermediaries are compensated through some combination of platform fees, device enablement fees, per-subscriber percentages, and revenue sharing. Streaming intermediaries do not build a platform like NBA League Pass and simply step aside-they are very much invested in a platform's continued global success and work with the content owner to determine how to sustain such growth. One such strategy, which is reflected profoundly in the collaboration between the NBA and NeuLion, has privileged a global address both within the United States and abroad. The NBA uses the international presence of NeuLion's platform to feature players and marketing that will simultaneously address the most possible fans in the most possible countries. The result is content that is international and inclusive, yet culturally vague. Intermediaries, then, are far from neutral in this process.

Sports provides a common thread across these examples. Over the past twenty years, as intermediary companies have influenced the development of global internet-distributed television, sports has been their most reliable and most lucrative client. Sports has been uniquely positioned to succeed within a media environment that has great need of live and spontaneous content. Victoria E. Johnson notes how, especially following the 2007-2008 Writers Guild strike, sports programming offered networks "a TiVo-proof, labor disputeproof, and recession-proof, historically stable, ritually available package (characterized by sport's seasonal and calendar regularity)." In addition, sports can be relatively easily repackaged with local commentary crews and local advertising, without modifying or adapting the content to the extent than one would a typical TV format. ${ }^{10}$ Geography, moreover, is central to sports. This is both in an additive sense, whereby distributors must package content for a specific market, and in a subtractive sense, in which regional blackouts prevent the airing of particular games in particular locations. In the era of internet TV, this process is conducted by the streaming intermediaries, which often emphasize their geolocation tools in their pitch to clients. As discussed later, sports has afforded these companies a level of experimentation and experience that has subsequently been put into use for other media owners, such as $\mathrm{HBO}$ and Univision.

\section{Intermediaries and Internet Television}

Starwave, founded in 1993 by Microsoft cofounder Paul Allen, sought to capitalize on content owners' eagerness to get online by leveraging its unique technological know-how. Together with ESPN, which served as the company's first and most important partner, Starwave offers an early instance of how intermediary services can influence and control the content that they distribute. The company, moreover, whose client base also included the NFL, NBA, ABC News, and Ticketmaster, helps to demonstrate how intermediaries and content owners work 
together and sets a precedent for future intermediaries such as BAMtech, NeuLion, and Ooyala. ${ }^{11}$ Just as intermediaries with the appropriate know-how are hired to build streaming platforms for their clients, Starwave was required to do the same for the ESPN website from the ground up. "We built all the tools-the technology to parse the data, and do the content management and the ad serving, and the load balancing," explains Mike Slade, former Starwave CEO, describing features which are now commonplace in web building and hosting platforms such as WordPress and SquareSpace. ${ }^{12}$ Completed in April 1995, the finished ESPN online platform was able to host score updates, photos, and featured audio and video highlights.

Tools were built for ESPNnet.SportZone.com, as it was then called, that allowed Starwave to analyze views and clicks. Starwave set cookies from the beginning to see who was coming, how often, and to which pages. Management could see, for instance, that traffic would peak on Monday morning when people at work could take advantage of high-speed connections at the office. This accumulated knowledge was essential to pitching advertisers on the value of internet advertising dollars over TV, print, or radio. Mike Slade recalls, "The whole pitch then ... wasn't 'this is a better presentation of your brand', it was 'you'll get all this data and someday you'll be able to sell direct to these people." "13 Starwave was able to parlay their data collection into extensive ad sales. Ad Age reported in October 1995 that Starwave had signed eight major sponsors to contracts totaling over US\$1 million, including a US\$300,000 deal with Levi Strauss and other smaller deals with AT\&T, Microsoft, and Pizza Hut. ${ }^{14}$ Streaming intermediaries today are not as significantly involved in the online ad sales business, which came to be dominated by Google and Facebook, but they continue to be in the data collection business, providing their accumulated insights to their clients. Like Starwave, today's streaming intermediaries pitch prospective clients on various proprietary tools that can track audience behavior ever more minutely. NeuLion's ability to track viewers-how many, how long, and where-on the NBA's international streaming platform has become essential to the NBA's ability to properly differentiate pricing in each market. These geolocation tools will be discussed more thoroughly in the section that follows.

Starwave's partnership with ESPN stipulated that ESPN be involved in any other sports endeavors, creating a three-way partnership with prospective clients, such as the NBA or the NFL, and splitting all advertising revenue three ways. The Starwave-ESPN platform remained under joint ownership of Starwave and ESPN, whereas the NBA leased its content and brand for the NBA platform. When Starwave set about programming its additional websites, the company simply cloned much of the original ESPN site and re-skinned it, and then worked in any unique requests made by their client. The NFL, for example, required a toolbar across the top of the page with all of the teams' logos, a feature that remained on the site until 2017. ${ }^{15}$ This three-way partnership, from the relatively early days of internet media, reflects the streaming paradigm to come. Even today, although the NBA's domestic League Pass, for instance, is emblazoned with the league's logos and branding, it is owned by Turner Sports Digital, just as Starwave and ESPN owned those early online platforms.

As Starwave's client base began to expand, so did their technological ambitions. A year after launching the NBA website in October 1995, Starwave gained the internet broadcast rights to the NBA, which allowed the company to stream audio of local broadcasts on the website. One game was to be offered for free every Thursday, with others available to pay subscribers. ${ }^{16}$ 
They also began a prototype for "Starwave TV," which was reported by Michael Malone of Fast Company in October 1996: "Imagine that you could watch the NBA finals on your computer, see footage of, say, Dennis Rodman going up for a rebound, touch the cursor to his moving figure-and instantly call up his entire career statistics." ${ }^{17}$ As bandwidth and other technological capabilities improved, other companies also began to see the potential for video streaming. AudioNet (later Broadcast.com) was cofounded by future Dallas Mavericks owner Mark Cuban in 1995. At its height, Broadcast.com boasted "the second-largest satellite-downlink facility in Texas," which featured "22 satellite dishes [that] receive content for more than 400 live events per day." To counter Starwave's acquisition of the NBA streaming rights, Broadcast.com obtained the rights to Major League Baseball, NCAA basketball, and the National Hockey League. ${ }^{19}$ In 1999, Yahoo! bought the company for US\$5.7 billion to bolster its nascent streaming operations. ${ }^{20}$

Disney purchased Starwave soon after taking control of ESPN. In April 1997, Disney announced that it was purchasing 33 percent of Starwave for approximately US\$100 million. Nearly a year to the day later, Disney exercised their option to buy out the remaining two-thirds of the company, folding Starwave's operations into its Buena Vista Internet Group to expand Disney's internet presence under a "common technology platform." ${ }^{21}$ Mike Slade had seen the move coming following Disney's purchase of ESPN parent, Cap Cities /ABC: "it was sort of obvious they were either going to dump us, which was impossible, or buy us." Starwave held too much leverage to exist independent of Disney's online operations and had to be brought in-house, whatever the cost.

Soon thereafter, Major League Baseball decided to go into the streaming business for itself, forming its Baseball Advanced Media (BAM) division in 2000 to look into building team websites and developing internet distribution in-house. The BAM division would later spin off its streaming operations into a public subsidiary, called BAMTech, having spent the prior fifteen years evolving into the premier intermediary company. ${ }^{22}$ For the same reasons that Disney bought up Starwave from 1997 to 1998, Disney would ultimately buy out BAMTech in August 2017, after BAMTech had become similarly intertwined in the streaming operations of ESPN.

Starwave played a significant role in expanding the possibilities of internet distribution, while it is also reflective of larger trends that would only reach maturity in the following two decades. In Joseph Turow's examination of this early experimental period of online advertising, he describes how executives saw the internet to be "a new way to gather relevant names and then reach out to those names quickly and efficiently," tracking users on "chat rooms and computer bulletin boards devoted to particular subjects." ${ }^{23}$ Starwave, through the data collected on its platforms, similarly offered advertisers insight into the online behavior of its users that could subsequently guide marketing plans.

On one hand, according to Philip Napoli, this media ecosystem has allowed for "substantial opportunities for audiences to interact with media," often in positive ways. On the other hand, these "interactive capacities" have ultimately worked to "facilitate the systemic gathering, aggregation, and analysis of information about these previously concealed dimensions of audience behavior." ${ }^{24}$ Starwave thus demonstrates the dialectic between greater consumer choices-the ability to access content anytime and anywhere-and greater corporate control. Streaming intermediaries and their clients, still very much beholden to the whims of advertising and the bottom line, have only more deeply integrated the tools that analyze 
consumer behaviors, folding the data back into how they guide and market to consumers and how much they charge them.

In Distribution Revolution, Michael Curtin, Jennifer Holt, and Kevin Sanson offer insight into the shift toward streaming media over the past decade and how it has affected the business models and power structures of the media conglomerates. The distribution revolution, they explain, "is changing the ways in which content is imagined, formulated, financed, produced, promoted, packaged, marketed, measured, delivered, interpreted, enjoyed, and recirculated," and moreover, it remains unclear who the "ultimate winners" will be. ${ }^{25}$ By charting the development of the streaming intermediary, one possible answer comes into focus that continues to privilege those parties with the infrastructural resources and the technological know-how, like the cable operators before them. The contemporary state of internetdistributed television is reflected in the actions of Starwave and the early internet startups. While their global ambitions were curtailed by a lack of bandwidth and reliable international infrastructures, the incentive for simultaneous globally distributed content had already become clear.

\section{Intermediaries and Global Television}

While Starwave, BAM, and Broadcast.com saw the possibilities of catering to global fans, the internet capacity and user base of the late 1990s could not reliably allow for it. Intermediaries today, however, such as NeuLion and BAMTech, are arguably positioned better for global streaming than for the domestic US market, which has had its streaming rights more extensively carved up by Turner, ESPN, NBC, and Fox Sports. In 2007, for instance, the NBA became the first sports league to comprehensively package together its linear and digital rights, when it renegotiated with Turner and ESPN. ${ }^{26}$ Globally, however, companies like NeuLion can work together directly with the NBA or with the NFL, who have retained their own nonUS streaming rights. Content owners, meanwhile, can maintain greater control over the international products while sharing less of the revenues.

While services like Netflix remain differentiated regionally by catalog, sports services have widely adopted a single uniform, inclusive "international" platform, which is then differentiated for each market by language. This is more easily accomplished for sports programming, which can flexibly substitute a local announcer team and local commercial breaks. By placing a single intermediary in charge of all non-US markets, moreover, this arrangement offers more oversight for the content owner and reduces the number of parties between the content provider and its central platform-managing intermediary. This paradigm is costeffective, then, if not particularly easy to manage. For that reason, NeuLion's process of localization is aided by satellite offices in many of the regions it oversees. NeuLion's office in China, for example, works with local clients and will relay the proper Chinese commercials to play during ad breaks. Despite these local markers, NBA's international League Pass remains an inclusive, globally efficient platform-there is a single shared platform for all fans outside of the United States. With an international League Pass subscription, Spanish viewers can watch the French feed or Portuguese fans can watch the Korean feed. This feature, however, is removed from the Turner-operated domestic platform. 
To identify a subscriber's location, intermediaries frequently rely on proprietary geolocation tools. Along with data analysis-a key contribution of the intermediary from the very beginninggeolocation has grown into a central tenet of its value for clients. Some intermediaries specialize specifically in those types of tools, which they offer to their customers. Joshua Braun differentiates between operations of geofencing, which allows clients such as Hulu and Netflix to "easily restrict access to their content to audiences in the regions they specify" and of geotargeting, which can "provide different versions of their content catalogues and interfaces to users in different markets." ${ }^{27}$ For sports intermediaries, geolocation is a fundamental part of their job, due to the "regional blackouts" triggered by broadcast rights, whereby a Knicks game cannot be streaming in the New York area or games offered by a national network like TNT (or even NBA TV) will not be offered in an area where that channel is available. The in-game support team at NeuLion will set those restrictions in the game's administrative tools once it is posted in their schedule.

Although the managers of international platforms aspire to genuine transnationality, allowing for engagement with various feeds across borders, platforms are still built on reinforcing borders through geolocation. Ramon Lobato articulates geoblocking as indicative of the contemporary global media ecosystem. In providing "an automated mechanism to enforce territorial licensing arrangements with rights-holders," geoblocking "is a form of access control enacted at the level of content and platform regulation." ${ }^{28}$ Although international streaming platforms, such as NBA League Pass and NFL Game Pass, are intended to be as uniform as possible across borders and market their own internationality, they remain dependent on the reinforcement of location awareness and differentiation. The value of these international passes and the intermediaries that build them is in tracking viewer behaviors, tagged by location, to price their services more aggressively or to leverage the data to advertisers. The most measurable remains, as ever, the most marketable. In The Informal Media Economy, Ramon Lobato and Julian Thomas describe the incentive for market segmentation, which "enables media producers to price their goods according to local income levels, to control sequencing and to extract the greatest return from each market." ${ }^{29}$ Companies like NeuLion make this possible in programming, designing, and managing the platforms and their measurement tools; the differentiation is built into the system.

As streaming increasingly comes to dominate TV distribution and US-based conglomerates seek international audiences over streaming platforms, this location awareness also reflects ongoing efforts to de-Americanize content for global distribution. While at the level of platform regulation geotargeting allows for the closing (and also opening) of borders, there is a simultaneous valuation and reinforcement of content that will most efficiently flow through those borders. Chuck Tryon describes the efforts of Netflix, in expanding into Latin and Europe, to acquire "local content that appeal to international audiences," which it achieved through agreements with Mexico's TV Azteca and Grupo Televisa and Brazil's Globo. ${ }^{30}$ The global presence of Netflix incentivizes the company to approve programming that will appeal to as many markets as possible at once. Similarly, Tanner Mirrlees argues that US transnational media companies "are de-Americanizing the content of TV shows and films so that they may more easily capture and control global, national, and trans-local lifestyle markets," rather than those that explicitly "promote one-dimensional or homogeneous images of "the American Way of Life' to the U.S. and to the wider world." ${ }^{1}$ Tanner Mirrlees, like Tryon, 
explains how this is often made easier through collaborations with local or regional conglomerates that have a deeper knowledge of local tastes. ${ }^{32}$

This collaborative localization is evident in the operations of streaming intermediaries, which work with client managers in satellite offices to solicit feedback from local audiences and relay any locally produced video that needs to be integrated into the completed product. The NBA and MLB, for instance, have both benefitted from high-profile international players that can be highlighted in replays. At the level of the regional sports networks (RSNs), whose broadcasts are circulated through the international streaming platforms, there have also been greater efforts to address international fans. The Milwaukee Bucks, for example, have worked to more extensively feature Greek star Giannis Antetokounmpo, which included airing a package produced by their Greek television partner that congratulated Antetokounmpo for making his first All-Star team in 2017. ${ }^{33}$ This goes hand in hand with the efforts of the intermediary, which has designed a platform that addresses any and all international fans simultaneously. By airing the package in-arena, it was broadcast worldwide through the NBA's streaming platform. Thus, a globally efficient product, created by the intermediary and the content owner in conjunction, encourages media producers to produce their content in particular ways (i.e., more inclusively international) while reinforcing a transnational approach to circulation.

Focusing on the intermediary in the context of global television is useful in complicating and clarifying how we conceptualize transnational flows and their directionality. On one hand, the work of the intermediary continues to reflect a one-way flow from US-based content owners and distributors to the rest of the world. Silvio Waisbord, writing in 2004, uses TV formats and their adaptability to emphasize how "traces of national belonging are downplayed and even eradicated," which results in "a pasteurized, transnational product detached from national cultures." ${ }^{\text {"S }}$ Similarly, by following the work of the intermediary in the age of streaming, there is evidence of this at the level of the platform. As streaming intermediaries produce their platforms like one would a TV format, which can be cloned or re-skinned for different regions and markets, there is a greater incentive for a more generalized or "pasteurized" transnational product. This is especially pronounced in cases like NBA League Pass, where there exists only a single international platform for all countries outside of the United States.

On the other hand, the greater transnational circulation of content allows for more extensive and multidirectional flows. This is evident in the example of the Milwaukee Bucks using content produced in Greece to better address international fans in their US broadcasts, knowing that their local RSN broadcast will be aired around the world through the NBA's streaming platform. It is also evident in the cross-cultural and dialogic possibilities opened up by "international" platforms, which allow fans in one country to view the feeds from any other. Michele Hilmes emphasizes the productive aspects of these global flows, arguing that "sweeping invocations of 'Americanization' or globalization tend to obscure the ways that cultural influence works, and always has worked, across lines of many different kinds ..."35 Intermediaries certainly support this claim, as they aid clients in building international fanbases and adjust their domestic TV output to do so.

But a one-way directionality, from the United States outward nonetheless persists, especially as US intermediaries are hired by non-US companies to put their content online. 
Ooyala, for instance, oversees the streaming platforms for Japanese sports network BJTV and Norwegian news network VGTV, among others. NeuLion's clients include China's CCTV, the United Kingdom's ITV, and Euroleague Basketball. In turn, these firms have become transnational companies, operating out of a web of regional satellite offices, but they are US-originated companies founded on neoliberal principles and incentives. Daya Kishan Thussu describes the growth of "contra-flows," the "flow of content from the global South to the North," that has been enabled by "the availability of digital technology, privatized and deregulated broadcasting, and satellite networks." He argues, however, that "the American hegemony of global media cultures" is ultimately strengthened by such a paradigm, as the localization of media content can "effectively legitimize the ideological imperatives of a freemarket capitalism." 36 The localization of the streaming platforms themselves, by US firms, only deepens the potential for such legitimization.

The combined flows of content and platform have also resulted in global jurisdictional uncertainties. Jack Goldsmith and Tim Wu have described the pressure placed by governments on internet "intermediaries" of various sorts-ISPs, search engines, credit card companies, and so on. ${ }^{37}$ Moreover, the lack of a strong and enforceable international law over content and data, Aaron Perzanowski and Jason Shultz explain, has resulted in these corporate intermediaries as the ultimate arbiters of law. End-user license agreements (EULA) thus come to "function as a form of privately made law that allows rights holders to modify, supplement, and contravene IP law at the expense of the customers who pay for their products." 38 Tarleton Gillespie has looked at these difficulties in relation to social media platforms, international in scope, which have variably obliged and ignored calls to remove content due to conflicting legal definitions. ${ }^{39}$ Streaming intermediaries, too, experience such pressures. NeuLion, for example, quickly pulled a movie trailer from a South American feed that featured nudity out of concern that it could violate content laws in countries with access to that feed.

Transnational flows, evidently, are not simply one-way or even straightforward in their multidirectionality. The intermediary, moreover, demonstrates that no longer do these flows derive from a simple producer-distributor agreement, but a more complex arrangement in which these companies significantly set and alter the terms by which global audiences engage with media content online. This global paradigm allows for content owners to profit from their content directly and to maintain greater control of it. In the realm of global internet distribution, these firms function as collaborative rights holders, just as Turner or Fox Sports might do for domestic US viewers. Without NeuLion, the NBA does not have the proper infrastructure to reach its global consumers. Without the NBA or other clients, NeuLion does not have the programming to fill its propriety platform. They require each other.

\section{Conclusion: Intermediaries, Sports, and Global Internet Television}

As BAMTech became more deeply involved in ESPN's preexisting streaming operations, as well as Disney's plans for a new standalone sports platform, the purchase became as likely as the purchase of Starwave twenty years earlier. Armed with a vast array of content, Disney is 
now ideally positioned to compete with Netflix and Amazon, using BAMTech's infrastructure and programming capabilities to distribute that content online, in-house, without the need of additional outside intermediaries. ${ }^{40}$

Even Amazon, whose prestigious Web Services division has been hired to provide cloud services for clients as diverse as Netflix and the US Central Intelligence Agency, found it necessary to purchase the Portland-based streaming intermediary Elemental Technologies for US\$500 million in September 2015. ${ }^{41}$ The absorption of Elemental into AWS has allowed Amazon to better compete in the business of streaming video encoding and transcoding, which features such competitors as BAMTech, NeuLion, and iStreamPlanet. The renamed AWS Elemental division provided Amazon with the tools and infrastructure necessary for its multiplatform Thursday Night Football offerings, following its agreement with the NFL. ${ }^{42}$ Disney's majority ownership of BAMTech thus allows them to bring their streaming infrastructure in-house and avoid any further reliance on AWS for streaming needs.

In trying to makes sense of global cultural flows and their directionality, streaming intermediaries offer scholars a perspective that is simultaneously industrial, cultural, and infrastructural. These firms oversee robust infrastructures of satellite and cabling that stretch around the world while also editing together content that circulates through their platforms and making sure that the final front-end feed is properly calibrated to each region. At the same time, streaming intermediaries operate as partners to major media companies and conglomerates, who entrust them with their content, sometimes to such an extent that the client is ultimately compelled to purchase the intermediary outright. As television continues to globalize and digitize, it is not a matter of if or when the intermediaries become as essential to the media ecosystem as cable operators and broadcast affiliates before them; that time is here. The age of streaming, and the role of intermediaries therein, is the fruition of twenty years of steady growth.

Sports has not been merely incidental to these developments. When Starwave began looking for prospective clients, sports offered an ideal fit. "Sports and money, and maybe travel, are the three businesses where you had a lot of exchange and a lot of time," recalls Mike Slade, "They have maybe the most complicated problems, in terms of real time data that changes a lot." In putting their content online, owners of sports content (teams, leagues, networks, etc.) required an intermediary service that could parse statistics, post highlights at a reasonable pace, and address geographical issues like blackouts. At the same time, sports offer interested distributors a massive amount of content-a basketball season, for example, features 2,460 games of approximately 2.5 hours, not including the playoffs. It is no surprise, then, that the top intermediaries all count sports providers among their clients. Sports has great need of streaming intermediaries for a number of issues, and that experience has proven vital as firms move on to work for nonsports projects from HBO, Disney, Univision, or ITV.

Sports, in turn, has occupied an important transitional space between the broadcast era of television and the needs of multiplatform programming. Victoria E. Johnson describes how sports represents "the most quintessential network-era programming" in its mass appeal and resonance while simultaneously reflecting the "individuated modes of address" and "a la carte packets of information" that are "characteristic of the post-network era." ${ }^{43}$ Sports television, Johnson argues, has historically provided a "familiarizing framework through which new 
delivery technologies (e.g., HDTVs) and new platforms for engaging television . . . are adopted." ${ }^{44}$ This necessitates our continued attention to streaming intermediaries, which undertake the work of programming and managing these platforms and delivery technologies.

Further research will be essential in more fully contextualizing the history of digital distribution and in illuminating the web of relations that make up the global media industries. The business of streaming intermediaries, and their role in contemporary media conglomeration, raises important questions about media competition and cultural flows. In March 2018, Endeavor, the parent company of Ultimate Fighting Championship (UFC) and Professional Bull Riders, both clients of NeuLion, purchased the company for US\$250 million. By taking control of NeuLion, Endeavor can bring the streaming operations of UFC in-house and offer direct-to-consumer services while continuing to provide services to the NBA, NFL, and other NeuLion clients. ${ }^{45}$ Streaming intermediaries have become highly in-demand for any conglomerate with greater aspirations of vertical integration.

There are many questions for scholars to consider in future research. How do streaming intermediaries contribute to the power of ISPs, given their presence within ComcastNBCUniversal (Playmaker Media) and Telstra (Ooyala)? What are the prospects for the success of independent firms, given NeuLion's recent absorption by Endeavor? What are the user experiences of these US-designed platforms in non-US markets (like NBA League Pass)? Despite efforts to internationalize sports programming, what distinct markers of American culture are perpetuated by the platform? Are these distinctions built into the interface? Are transnational products different from those managed by local firms? Such scholarship will be crucial in further illuminating the operations of the often-obscure intermediaries. In doing so, as high-profile firms continue to make headlines and as their services occupy an increasingly central position within major media conglomerates, these formerly invisible entities will be brought more fully into the spotlight.

${ }^{1}$ Steven Secular is a PhD candidate in Film and Media Studies at the University of California, Santa Barbara. His research focuses on the history and globalization of the sports television industry. His dissertation charts the evolution of the National Basketball Association and its global investment in cable, satellite, and digital technologies.

${ }^{2}$ Sarah Perez, "BAMTech Valued at \$3.75 Billion Following Disney Deal," TechCrunch, August 8, 2017, https://techcrunch.com/2017/08/08/bamtech-valued-at-3-75billion-following-disney-deal/.

${ }^{3}$ Amanda D. Lotz, Portals: A Treatise on Internet-Distributed Television (Ann Arbor, MI: Maize Books, 2017), 8.

${ }^{4}$ Joshua Braun, "Transparent Intermediaries: Building the Infrastructures of Connected Viewing," in Connected Viewing: Selling Streaming, and Sharing Media in the Digital Era, ed. Jennifer Holt and Kevin Sanson (NY: Routledge, 2014), 125, 138.

${ }^{5}$ Amanda D. Lotz, The Television Will Be Revolutionized, 2nd ed. (NY: New York University Press, 2014), 153.

${ }^{6}$ Wired Staff, "Wary Microsoft Partners Take Pragmatic Path," Wired, March 14, 1997, https://www.wired.com/1997/03/wary-microsoft-partners-take-pragmatic- 
path/; "BackWeb to Push to Big Browsers," CNET, August 20, 1997, https://www. cnet.com/news/backweb-to-push-to-big-browsers/.

${ }^{7}$ John Ourand, "NBC Sports Enters Video Streaming Business with Playmaker," SportsBusiness Journal, May 23, 2016, http://www.sportsbusinessdaily.com/ Journal/Issues/2016/05/23/Media.

${ }^{8}$ Jason Dachman, "NBC's Playmaker Media, Turner's iStreamPlanet Team Up to Compete with BAMTech," Sports Video Group, January 9, 2017, https://www. sportsvideo.org/2017/01/09/.

${ }^{9}$ Victoria E. Johnson, "Everything New is Old Again: Sport Television, Innovation, and Tradition for a Multi-Platform Era," in Beyond Prime Time: Television Programming in the Post-Network Era, ed. Amanda D. Lotz (NY: Routledge, 2009), 114.

${ }^{10}$ Michael Keane, Anthony Y. H. Fung, and Albert Moran, New Television, Globalization, and the East Asian Cultural Imagination (Aberdeen: Hong Kong University Press, 2007), 74.

${ }^{11}$ Ooyala's board of advisors, in fact, includes former Starwave senior vice president Tom Phillips.

12 Mike Slade, in discussion with the author, September 12, 2017.

${ }^{13}$ Ibid.

${ }^{14}$ Debra Aho Williamson, "Score One for ESPN, Starwave," Ad Age, October 2, 1995, http://adage.com/article/news/score-espn-starwave/21/.

15 "Welcome to the New, Improved Home of the NFL," NFL.com, July 25, 2017, http:// www.nfl.com/news/story/0ap3000000821751/article/welcome-to-the-newimproved-home-of-the-nfl.

${ }^{16}$ David Lazarus, "Starwave Scores Online NBA Broadcast Rights," Wired, December 9, 1996, https://www.wired.com/1996/12/starwave-scores-online-nba-broadcastrights /.

${ }^{17}$ Michael S. Malone, "Starwave Takes the Web ... (Seriously)," Fast Company, October 31, 1996, https://www.fastcompany.com/27448/starwave-takes-web-seriously.

${ }^{18}$ Eric Ransdell, "Broadcast.com Boosts Its Signal," Fast Company, July 31, 1998, https://www.fastcompany.com/34608/broadcastcom-boosts-its-signal.

${ }^{19}$ Ibid.

${ }^{20}$ Kara Swisher and Evan Ramstad, "Yahoo! to Announce Acquisition of Broadcast. com for \$5.7 Billion," Wall Street Journal, April 1, 1999, https://www.wsj.com/ articles/SB922916873273123235.

21 "Disney Wishes on Starwave," CNN Money, April 30, 1998, http://money.cnn. com/1998/04/30/technology/disney/.

${ }^{22}$ Ben Popper, "How Baseball's Tech Team Built the Future of Television," The Verge, August 4, 2015, https://www.theverge.com/2015/8/4/9090897/mlb-bam-livestreaming-internet-tv-nhl-hbo-now-espn.

${ }^{23}$ Joseph Turow, Niche Envy: Marketing Discrimination in the Digital Age (Cambridge: MIT Press, 2006), 73-74.

${ }^{24}$ Philip M. Napoli, Audience Evolution: New Technologies and the Transformation of Media Audience (NY: Columbia University Press, 2011), 8-9.

${ }^{25}$ Ibid., 4-5.

${ }^{26}$ Dawn C. Chmielewski and Greg Johnson, "NBA Contract Takes Digital Leap Forward," Los Angeles Times, June 28, 2007, http://articles.latimes.com/2007/jun/28/ business /fi-espn28. 
${ }^{27}$ Braun, "Transparent Intermediaries," 126.

${ }^{28}$ Ramon Lobato, "Introduction: The New Video Geography," in Geoblocking and Global Video Cultures, ed. Ramon Lobato and James Meese (Amsterdam: Institute of Networked Cultures, 2016), 10.

${ }^{29}$ Ramon Lobato and Julian Thomas, The Informal Media Economy (Cambridge: Polity Press, 2015), 105.

${ }^{30}$ Chuck Tryon, On-Demand Culture: Digital Delivery and the Future of Movies (New Brunswick, NJ: Rutgers University Press, 2013), 47-48.

${ }^{31}$ Tanner Mirrlees, Global Entertainment Media: Between Cultural Imperialism and Cultural Globalization (NY: Routledge, 2013), 207.

32 Ibid., 101.

${ }^{33}$ Mike Chant (Senior Director, Team Programming, NBA), in discussion with the author, November 13, 2017.

${ }^{34}$ Silvio Waibord, "McTV: Understanding the Global Popularity of Television Formats," TelevisionENewMedia5(4,November2004):359-383.doi:10.1177/1527476404268922.

${ }^{35}$ Michele Hilmes, Network Nations: A Transnational History of British and American Broadcasting (London: Routledge, 2011), 310.

${ }^{36}$ Daya Kishan Thussu, "Mapping Global Media Flow and Contra-Flow," in Media on the Move: Global Flow and Contra-Flow, ed. Daya Kishan Thussu (London: Routledge, 2007), 23, 28.

${ }^{37}$ Jack Goldsmith and Tim Wu, Who Controls the Internet? Illusions of a Borderless World (Oxford: Oxford University Press, 2006), 68-72.

${ }^{38}$ Aaron Perzanowski and Jason Schultz, The End of Ownership: Personal Property in the Digital Economy (Cambridge: MIT Press, 2016), 58-59.

${ }^{39}$ Tarleton Gillespie, "Governance of and by Platforms," in The SAGE Handbook of Social Media, ed. Jean Burgess, Thomas Poell, and Alice Marwick (Thousand Oaks, CA: SAGE, 2018).

${ }^{40}$ Ben Popper, "Disney Bought Baseball's Tech Team to Take on Netflix," The Verge, August 9, 2017, https://www.theverge.com/2017/8/9/16118694/disney-bamtech-espn-streaming-netflix.

${ }^{41}$ Connie Loizos, "Amazon Acquires Elemental Technologies For a Reported \$500 Million in Cash," TechCrunch, September 3, 2015, https://techcrunch. com/2015/09/03/amazon-acquires-elemental-technologies-for-a-reported500-million-in-cash/.

${ }^{42}$ Ken Kerschbaumer, "AWS Elemental Takes Next Step Forward with Media Services Offering," Sports Video Group, November 26, 2017, https://www.sportsvideo. org/2017/11/26/aws-elemental-takes-next-step-forward-with-media-servicesoffering/.

${ }^{43}$ Victoria E. Johnson, "Everything New is Old Again," 115-16.

${ }^{44}$ Ibid., 122.

45 Andrew Wallenstein, "Endeavor Buys Streaming Provider NeuLion for \$250 Million," Variety, March 26, 2018, http://variety.com/2018/biz/news/endeavor-buysstreaming-provider-neulion-for-250-million-1202736768/. 


\section{Bibliography}

Braun, Joshua. "Transparent Intermediaries: Building the Infrastructures of Connected Viewing." In Connected Viewing: Selling Streaming, and Sharing Media in the Digital Era, edited by Jennifer Holt and Kevin Sanson, 124-43. New York: Routledge, 2014.

Curtin, Michael, Jennifer Holt, and Kevin Sanson. Distribution Revolution: Conversations about the Digital Future of Film and Television. Oakland: University of California Press, 2014.

Gillespie, Tarleton. "Governance of and by Platforms." In The SAGE Handbook of Social Media, edited by Jean Burgess, Thomas Poell, and Alice Marwick. Thousand Oaks, CA: SAGE, 2018.

Goldsmith, Jack and Tim Wu. Who Controls the Internet? Illusions of a Borderless World. Oxford: Oxford University Press, 2006.

Hilmes, Michele. Network Nations: A Transnational History of British and American Broadcasting. London: Routledge, 2011.

Johnson, Victoria E. "Everything New is Old Again: Sport Television, Innovation, and Tradition for a Multi-Platform Era." In Beyond Prime Time: Television Programming in the PostNetwork Era, edited by Amanda D. Lotz, 114-37. New York: Routledge, 2009.

Keane, Michael, Anthony Y. H. Fung, and Albert Moran, New Television, Globalisation, and the East Asian Cultural Imagination. Aberdeen: Hong Kong University Press, 2007.

Lobato, Ramon. "Introduction: The New Video Geography." In Geoblocking and Global Video Cultures, edited by Ramon Lobato and James Meese, 10-22. Amsterdam: Institute of Networked Cultures, 2016.

Lobato, Ramon, and Julian Thomas. The Informal Media Economy. Cambridge: Polity Press, 2015.

Lotz, Amanda D. Portals: A Treatise on Internet-Distributed Television. Ann Arbor, MI: Maize Books, 2017.

Lotz, Amanda D. The Television Will Be Revolutionized. 2nd ed. New York: New York University Press, 2014.

Mirrlees, Tanner. Global Entertainment Media: Between Cultural Imperialism and Cultural Globalization. New York: Routledge, 2013.

Napoli, Philip M. Audience Evolution: New Technologies and the Transformation of Media Audience. New York: Columbia University Press, 2011.

Perzanowski, Aaron, and Jason Schultz. The End of Ownership: Personal Property in the Digital Economy. Cambridge: MIT Press, 2016.

Thussu, Daya Kishan. "Mapping Global Media Flow and Contra-Flow." In Media on the Move: Global Flow and Contra-Flow, edited by Daya Kishan Thussu, 11-32. London: Routledge, 2007.

Tryon, Chuck. On-Demand Culture: Digital Delivery and the Future of Movies. New Brunswick, NJ: Rutgers University Press, 2013.

Turow, Joseph. Niche Envy: Marketing Discrimination in the Digital Age. Cambridge: MIT Press, 2006.

Waibord, Silvio. "McTV:Understanding the Global Popularity of Television Formats." Television \& New Media 5, no. 4 (November 2004): 359-383. doi:10.1177/1527476404268922. 